\title{
TWO NEW SPIDER MITES (ACARI, PROSTIGMATA, TETRANYCHIDAE) FROM SOUTH AMERICA
}

\author{
Carlos H.W. Flechtmann ${ }^{1}$
}

\begin{abstract}
Oligonychus viranoplos, sp.n. from a bamboo (Poaceae) from Piracicaba, São Paulo, Brasil and Eotetranychus vinealis, sp.n. from Vitis vinifera L. (Vitaceae) from Cerrito, Valle, Colombia, are described.

KEY WORDS. Acari, new species, bamboo, vineyard, spider mites, South America
\end{abstract}

In the course of investigating the spider mite fauna of cultivated plants, two species new for Science were found.

\section{Oligonychus viranoplos, sp.n.}

Figs 1-10

The aedaeagus resembles that of $O$.perditus Pritchard \& Baker, 1955 but, differs in the absence of a mediodorsal notch near the base of the external portion of the shaft, present in the latter species. Tarsus I presents one pair of tactile setae ventrally beyond the duplexes (two pairs in perditus).

Female (Figs 1-5). Body, including rostrum, 386 um long $(n=10$; range: 338-429); 256 um wide ( $\mathrm{n}=7$; range 234-273). Colour, in life, dark orange-greenish, tarsi I-IV and tibia I orange; other leg segments translucent. Idiosoma with setae slender, pubescent, longer than distances between basis of consecutive setae. Cuticular striae transverse dorsomedially, tending to form a slight inverted $\mathrm{V}$ pattern between setae $\mathrm{DC}_{3}\left(\mathrm{c}_{1}\right)$. Peritremes ending in a small hook. Genital flap transversely striated; area immediately anterior longitudinally striated. Terminal sensillum of palp tarsus strong, about one and half times as long as wide. Legs: distribution of setae and solenidia (in parentheses) on leg segments, from coxae to tarsi:

$$
\begin{aligned}
& \text { I }-2-1-8-5-7(1)-2 \text { dupl. }+12(1) \\
& \text { II }-2-0-6-5-5 \quad-1 \text { dupl. }+12(1) \\
& \text { III }-1-1-2-2-5-8(1) \\
& \text { IV }-1-1-1-2-5-8(1)
\end{aligned}
$$

Tarsus I with four sensory setae and one solenidion proximal to proximal duplex setae; one sensory seta ventral to duplexes. Tibia I with seven tactile setae and

1) Departamento de Zoologia, Escola Superior de Agricultura "Luiz de Queiroz", Universide São Paulo, Caixa Postal 9, 13418-900 Piracicaba, São Paulo, Brasil. CNPq fellow. 


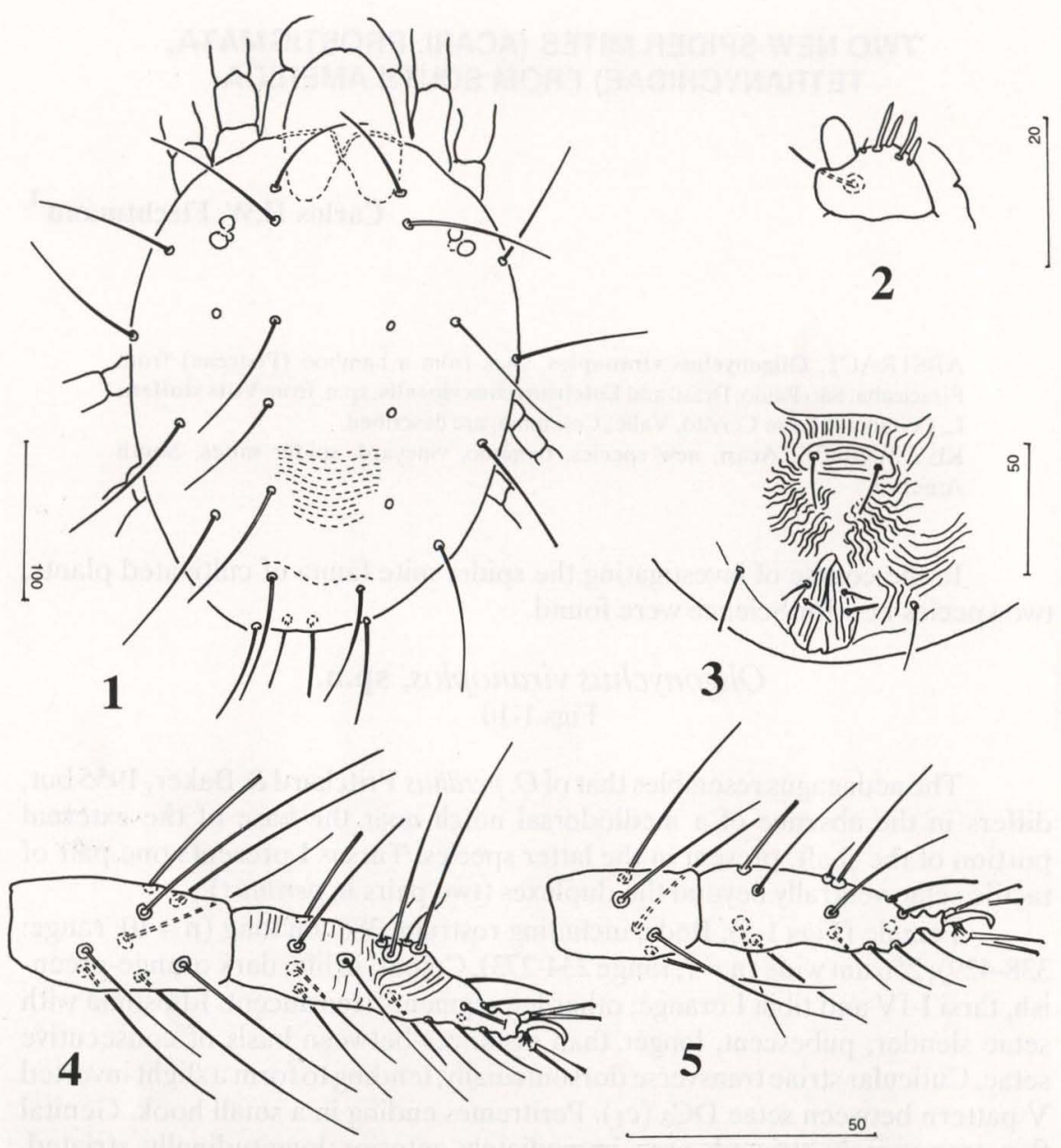

Figs 1-5. Oligonychus viranoplos, sp.n., female. (1) Dorsal aspect; (2) palp tarsus; (3) genito-anal area; (4) tarsus and tibia I; (5) tarsus and tibia II.

one solenidion; tibia II with five tactile setae. Empodium a well developed claw, with proximo-ventral hairs.

Male (Figs 6-10). Body, including rostrum, 336 um long $(n=10$; range 325-364). Palp tarsus presents no proeminent terminal sensillum; in its place a small circular, slightly depressed, area. Distribution of setae and solenidia (in parentheses) on leg segments, from coxae to tarsi:

$$
\begin{aligned}
& \text { I }-2-1-8-5-7(3)-2 \text { dupl. }+12(2) \\
& \text { II }-2-1-6-5-5 \quad-1 \text { dupl. }+12(1) \\
& \text { III }-1-1-2-2-5-8(1) \\
& \text { IV }-1-1-1-2-5-8(1)
\end{aligned}
$$


Tarsus I with four tactile setae and two solenidia proximal to proximal duplex setae; tarsus II with three sensory setae and one solenidion proximal to duplex. Tibia I with eight sensory setae and two solenidia; tibia II with five sensory setae. Aedaeagus with distal one third bent ventrad, at a right angle, the terminal portion slightly curved and narrowed, however, not ending in an acute tip.

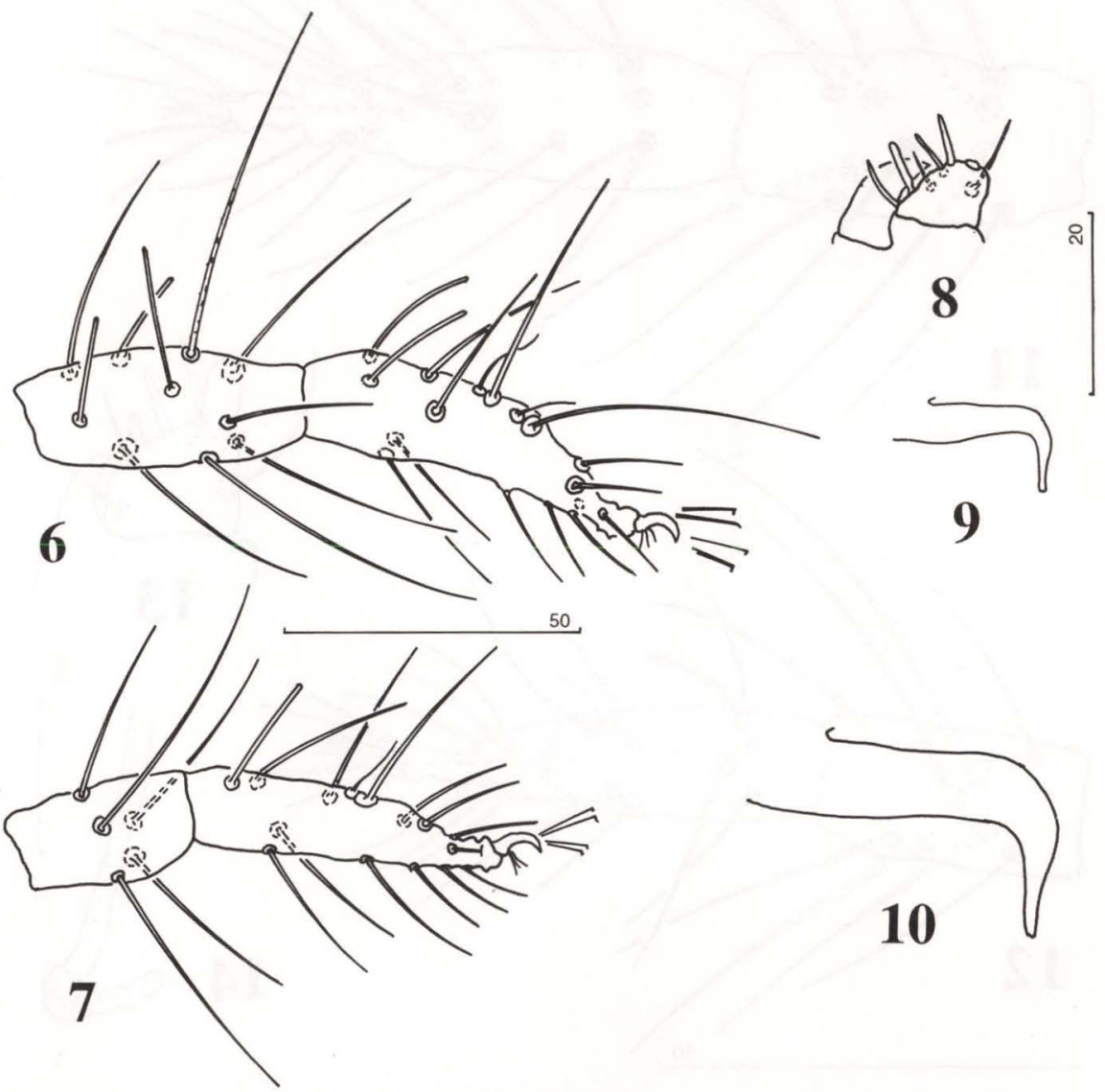

Figs 6-10. Oligonychus viranoplos, sp.n., male. (6) Tarsus and tibia I; (7) tarsus and tibia II; (8) palp tarsus; (9) aedaeagus; (10) aedaeagus, greatly enlarged.

Holotype male, six paratype males and 10 paratype females, from bamboo, Piracicaba, São Paulo, Brazil (C.H.W. Flechtmann leg.), May 24, 1993. In the author's collection in the Department of Zoology, University of São Paulo, ESALQ, Piracicaba, São Paulo.

Etymology. Viranoplos, from the Latin Vir (male), and the greek anoplos (unarmed), referring to the absence of the terminal sensillum in the palp tarsus. 


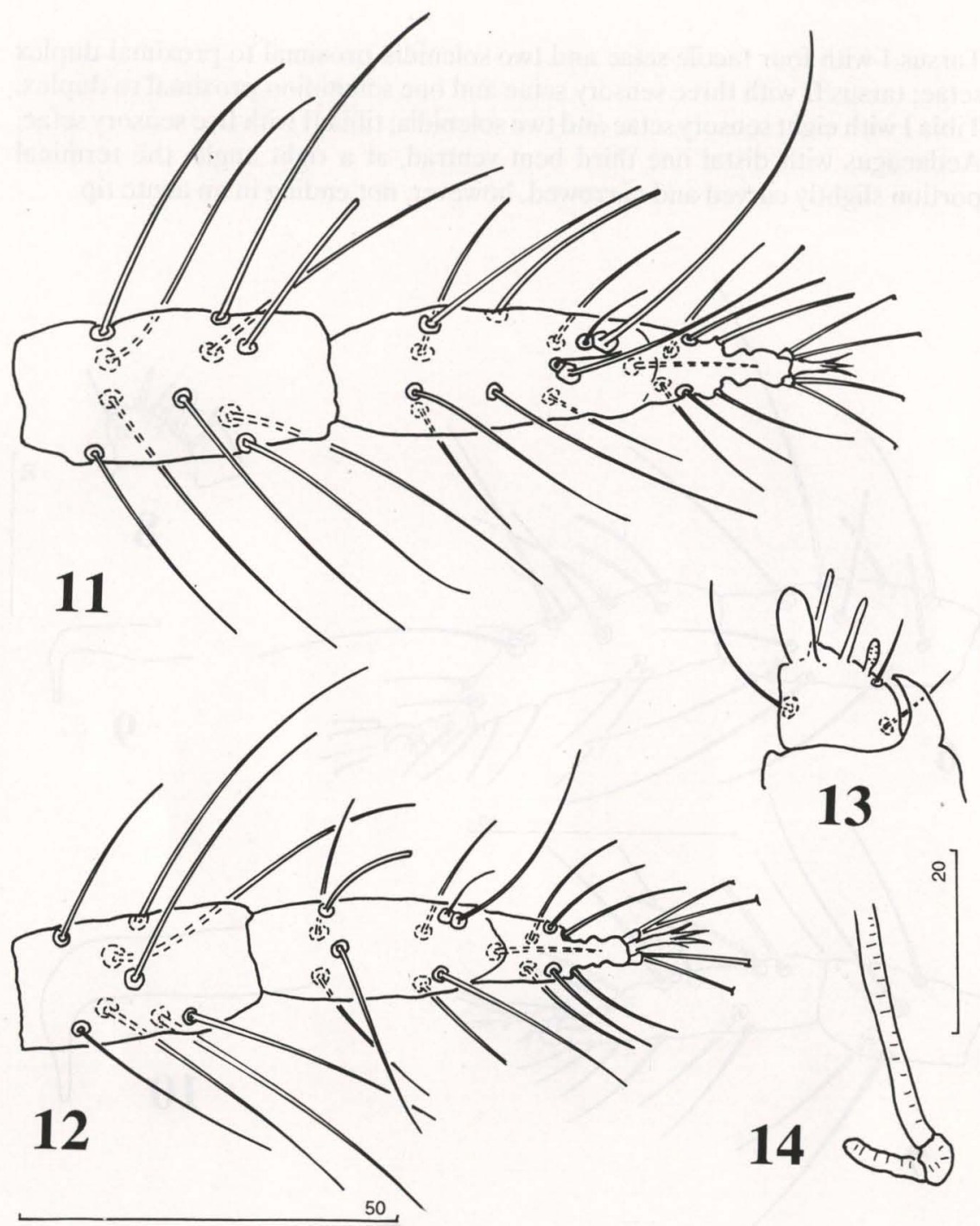

Figs 11-14. Eotetranychus vinealis, sp.n., female. (11) Tarsus and tibia I; (12) tarsus and tibia II; (13) palp tarsus; (14) peritreme.

\section{Eotetranychus vinealis, sp.n.}

Figs 11-19

The aedaeagus is somewhat similar to that of E. spectabilis Ehara, 1987, but the male terminal sensillum of the palp tarsus is a small cone and not slender and elongate as in the latter species; tibia I of male bears 8 tactile setae and 3 solenidia instead of only 8 tactile as in spectabilis. The aedaeagus also resembles 


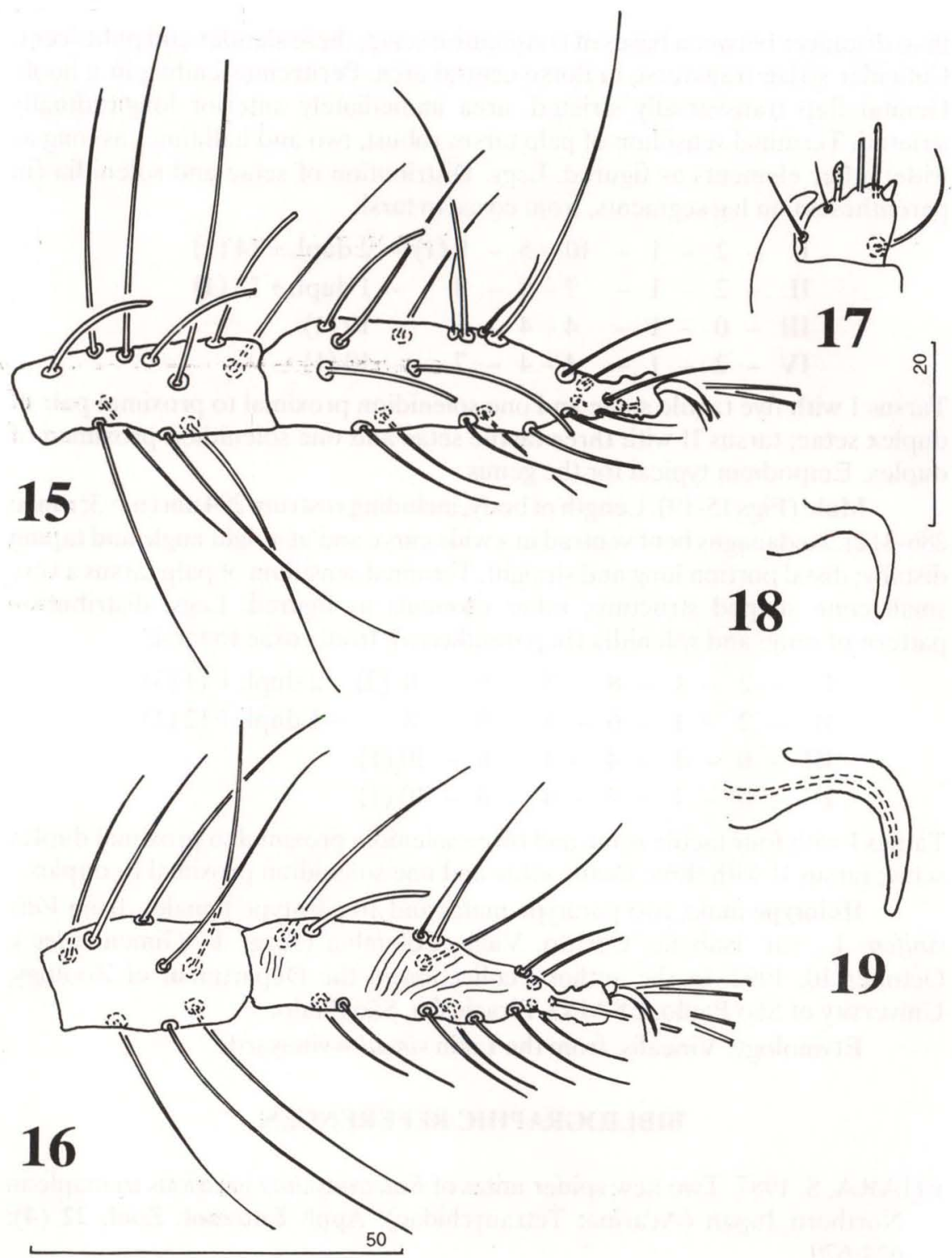

Figs 15-19. Eotetranychus vinealis, sp.n., male. (15) Tarsus and tibia I; (16) tarsus and tibia II; (17) palp tarsus; (18) aedaeagus; (19) aedaeagus, greatly enlarged.

that of E. nigrens Flechtmann \& Baker, 1970, but differs also by the terminal sensillum of the palp tarsus; tibia I in this species has 9 tactile setae and one solenidion.

Female (Figs 11-14). Body, including rostrum, 355 um long ( $\mathrm{n}+10$; range 312-416); 198 um wide $(\mathrm{n}=10$; range 182-247). Idiosoma with dorsal setae longer 
than distances between bases of consecutive setae; these slender and pubescent. Cuticular striae transverse in dorso central area. Peritremes ending in a hook. Genital flap transversally striated, area immediately anterior longitudinally striated. Terminal sensillum of palp tarsus robust, two and half times as long as wide; other elements as figured. Legs. Distribution of setae and solenidia (in parentheses) on leg segments, from coxae to tarsi:

$$
\begin{aligned}
& \text { I }-2-1-10-5-9(1)-2 \text { dupl. +14 (1) } \\
& \text { II }-2-1-7-5-8-1 \text { dupl. +13(1) } \\
& \text { III }-0-1-4-4-6-10(1) \\
& \text { IV - } 2-1-4-4-7-10(1)
\end{aligned}
$$

Tarsus I with five tactile setae and one solenidion proximal to proximal pair of duplex setae; tarsus II with three tactile setae and one solenidion proximad of duplex. Empodium typical for the genus.

Male (Figs 15-19). Length of body, including rostrum $294 \mathrm{um}(\mathrm{n}=3$; range 286-312). Aedaeagus bent ventrad in a wide curve and at a right angle and taping distally; distal portion long and straight. Terminal sensillum of palp tarsus a very small cone shaped structure; other elements as figured. Legs: distribution pattern of setae and solenidia (in parentheses), from coxae to tarsi:

$$
\begin{aligned}
& \text { I }-2-1-8-5-5-8(3)-2 \text { dupl. }+14(3) \\
& \text { II }-2-1-6-5-8-8-1 \text { dupl. }+12(1) \\
& \text { III }-0-1-4-4-6-10(1) \\
& \text { IV }-0-1-4-4-6-10(1)
\end{aligned}
$$

Tarsus I with four tactile setae and three solenidia proximal to proximal duplex setae; tarsus II with three tactile setae and one solenidion proximal to duplex.

Holotype male, two paratype males and 10 paratype females, from Vitis vinifera L., var. Isabelle, Cerrito, Valle, Colombia (Jorge E. Gimenez leg.), October 10, 1992. In the author's collection in the Department of Zoology, University of São Paulo, ESALQ, Piracicaba, São Paulo.

Etymology. Vinealis, from the Latin vineal = vineyard.

\section{BIBLIOGRAPHIC REFERENCES}

EHARA, S. 1987. Two new spider mites of Eotetranychus injurious to maple in Northern Japan (Acarina: Tetranychidae). Appl. Entomol. Zool. 22 (4): 624-629.

FLECHTMANN, C.H.W. \& E.W. BAKER. 1970. A preliminary report on the Tetranychidae (Acarina) of Brazil. Ann. Entomol. Soc. Amer. 63 (1): 156-163.

PRITCHARD, A.E. \& E.W. BAKER. 1955. A revision of the spider mite family Tetranychidae. Pacif. Coast Entomol. Soc. Mem. 2: 1-472. 